\title{
Reprogramming of mouse embryonic fibroblasts into induced oligodendrocyte progenitor cells via nanovector-mediated indirect lineage conversion
}

Xiong Xiao ( $\sim$ y1982@swu.edu.cn )

Southwest University https://orcid.org/0000-0001-8958-8864

Wen-Hui Ling

Southwest University

Xiao-Yan Qiu

Southwest University

Ming-Yu Wang

Southwest University

Chun-Xia Xiong

Southwest University

Deng-Feng Xie

Southwest University

Xin-Yue Chu

Southwest University

Yun-Xin Li

Southwest University

Yun Huang

Southwest University

Tong Li

Southwest University

Yue-Min Li

Southwest University

\section{Research}

Keywords: Indirect lineage conversion, Nanovector, Induced oligodendrocyte progenitor cells (iOPCs), Oligodendrocytes (OLs), Reprogramming

Posted Date: June 17th, 2020

DOI: https://doi.org/10.21203/rs.3.rs-35533/v1 
License: (c) (i) This work is licensed under a Creative Commons Attribution 4.0 International License. Read Full License 


\title{
Reprogramming of mouse embryonic fibroblasts into induced oligodendrocyte progenitor cells via nanovector-mediated indirect lineage conversion
}

\author{
Xiong Xiao"**, Wen-Hui Ling", Xiao-Yan Qiu, Ming-Yu Wang, Chun-Xia Xiong, Deng-Feng Xie, \\ Xin-Yue Chu, Yun-Xin Li, Yun Huang, Tong Li and Yue-Min $\mathrm{Li}^{*}$
}

\begin{abstract}
\# Xiong Xiao and Wenhui Ling contributed equally to this work.
*Correspondence: y1982@swu.edu.cn; 819587402@qq.com

Department of veterinary medicine, College of Animal Science and Technology, Southwest University, Chongqing 400715, China
\end{abstract}

Full list of author information is available at the end of the article

\begin{abstract}
Background: Axon-wrapping myelin sheath is vital to nerve conduction, loss or dysfunction of it will result in some neurological diseases. Since mature oligodendrocytes (OLs) lack proliferation ability, and oligodendrocyte progenitor cells (OPCs) maintain slow proliferation or quiescence state, transplantation of exogenous OPCs becomes an alternative strategy for curing these diseases.
\end{abstract} Methods: OPCs were isolated from brain tissue and generated from NIH/3T3 cells via indirect lineage conversion here. Results: $0.25 \%$ chicken serum was conducive to trypsin-mediated digestion of cerebral cortex, the modified shaking method could improve the purification efficiency of OPCs. Poly-MAG was a safer and higher efficient nanovector for delivering plasmid DNA into cells. Forced expressions of Olig 2, Nkx 6.2, and Sox 10 could attenuate the expressions of fibroblast-related genes (Col5al and Colla1), up-regulate OPC-associated genes (PDGFR , $S 100 \beta, N G 2$, and Olig 2), and finally successfully reprogram NIH/3T3 cells into induced oligodendrocyte progenitor cells (iOPCs). $1 \mu \mathrm{M}$ haloperidol (HAL) contributed to promoting the proliferation of iOPCs. These iOPCs had the potential to be differentiated into OLs and type II astrocytes. Conclusions: The high-efficiency and low-cytotoxicity strategies for isolating mouse primary OPCs and generating iOPCs were established, which provided novel cell resources for disease modeling, drug screening, cell therapy, and so on.

Keywords: Indirect lineage conversion, Nanovector, Induced oligodendrocyte progenitor cells (iOPCs), Oligodendrocytes (OLs), Reprogramming 


\section{Background}

Millions of people are suffering from myelin-related diseases, such as multiple sclerosis, congenital leukodystrophy, and Guillain-Barré syndrome, which are currently uncurable by drugs, cell therapy is an alternative and promising strategy for completely repairing the damaged myelin. OLs are the main myelin-generating cells in the central nerve system (CNS), but transplantation of them is very hard to cure these diseases for their limited proliferation ability and allograft-induced immunological rejection [1]. OPCs can proliferate and differentiate into OLs, transplantation of them is a therapeutic option for demyelinating diseases. However, native OPCs in adult brain accounts for only $5 \%$ to $8 \%$ of cells in the white matter, and unfortunately, they usually maintain a state of slow proliferation or quiescence, it is necessary to modify the traditional isolation system of primary OPCs to obtain enough cells for transplantation. With the increase of age, the proportion and proliferation ability of OPCs in vivo are inclined to decrease, more OPCs may be harvested from fetus before birth. The main tissue for isolating primary OPCs is cerebral cortex, in contrast to skin tissue, it is soft and easy to be damaged in vitro, when it is digested by $0.25 \%$ trypsin, the quality and quantity of OPCs may decline. Chicken serum, unlike most mammalian sera with trypsin inhibitor, performs a cell-protective role, which will contribute to improving the viability of OPCs. In addition, traditionally long-time shaking for $16 \mathrm{~h}$ to $18 \mathrm{~h}$ at high speed usually induced the damage even death of early exfoliative OPCs. Therefore, effects of different gestational ages, digestion methods, and purification strategies on mouse OPCs were explored here to improve the isolation and culture system of primary OPCs.

In addition to isolating primary OPCs from cerebral cortex, indirect lineage conversion technology provides a safe, efficient, and novel strategy for obtaining OPCs. Autologous iOPCs with self-renewal and differentiation potentials can be generated from differentiated cells via forced expressions of neuro-related transcription factors. However, so far these foreign genes were delivered mostly via retrovirus or lentivirus [2-4], which limited the clinical applications of these iOPCs for the potential biosafety hazards. As the novel non-viral transgenic vector, magnetic iron oxide nanoparticles (MIONs) can evade these hazards, furthermore, they have low immunogenicity and can protect plasmid DNA (pDNA) against lysosomal enzymes and DNAase, which contribute to improving the transfection efficiency. Poly-MAG (a kind of polyethyleneimine (PEI)-coated MIONs), Lipofectamine 2000, and Lipofectamine LTX were 
compared here to deliver oligodendrocyte lineage transcription factor 2 (Olig 2)-encoding pDNA into NIH/3T3 cells, which aimed to establish an efficient and non-viral gene-delivering system for generating iOPCs.

Using Poly-MAG-mediated transfection system, different combinations of Olig 2, NK 6 homeobox transcription factor 2 (Nkx 6.2), and sex-determining region Y-related high-mobility group box 10 (Sox 10) were attempted to reprogram NIH/3T3 cells into iOPCs. After being screened by G418, enhanced green fluorescent protein $(\mathrm{EGFP})^{+}$cells were cultured in OPC proliferation medium and identified with morphology observation, expressions of specific marker genes, and induced differentiation, OPC-like iOPCs were successfully generated. Therefore, the isolation and purification system of primary OPCs were optimized, and the nanovector-mediated indirect lineage transformation technology system for high-efficiently harvesting iOPCs was established in this study, which laid the foundation for basic researches, cell therapy, disease modeling, drug development, and so on.

\section{Materials \& methods}

\section{Materials}

Kunming mice and NIH/3T3 cells were purchased from Chongqing Institute of Chinese Materia Medica in China and Shanghai Institute of Biochemistry and Cell Biology, respectively. The animal experiments were accepted by Institutional Animal Care and Use Committee of Southwest University.

\section{Isolation, culture, purification, and passage culture of mouse OPCs}

Brain cortex was isolated from mouse fetus at the gestational age of 18.5 days or 1 day old neonatal mouse. Tissues were digested with trypsin and chicken serum as listed in Extended Table 1. These dispersed cells were cultured in DMEM culture medium (DMEM supplemented with 0.1 $\mathrm{mM} \beta$ - mercaptoethanol, $2 \mathrm{mM}$ glutamine, $1 \mathrm{mM}$ sodium pyruvate, $10 \%$ fetal bovine serum, and $100 \mathrm{U} / \mathrm{mL}$ penicillin-streptomycin mixed solutions (PS)). Trypan Blue exclusion method was used to analyze the cell viability. After being cultured at $37{ }^{\circ} \mathrm{C}$ for $40 \mathrm{~min}$, fibroblasts would adherent to flask, then the supernatant was carefully transferred into $0.1 \mathrm{mg} / \mathrm{mL}$ poly-L-lysine-coated culture flask. After being continually cultured for 7-9 days, OPCs were mainly located in the upper layer, however, the vast majority of astrocytes were found in the under 
layer, which contributed to the purification of OPCs.

After being shaken at $37{ }^{\circ} \mathrm{C}, 160 \mathrm{rpm}$ for $2 \mathrm{~h}$, these adherent cells were rinsed with PBS and cultured for $2 \mathrm{~h}$. Two schemes were applied to purify OPCs as following: (1) Cells were shook at $37{ }^{\circ} \mathrm{C}, 250 \mathrm{rpm}$ for $16-18 \mathrm{~h}$, cells in the supernatant were collected and cultured in OPC proliferation medium (DMEM supplemented with $1 \times \mathrm{N}-2$ Max, $1 \times \mathrm{B}-27,2 \mathrm{mM}$ glutamine, 20 $\mathrm{ng} / \mathrm{mL}$ fibroblast growth factor (FGF), $20 \mathrm{ng} / \mathrm{mL}$ platelet derived growth factor (PDGF)-AA, and $100 \mathrm{U} / \mathrm{mL}$ PS). After being incubated for $30 \mathrm{~min}$, fibroblasts would adhere on the uncoated culture flask, then cell suspension containing OPCs was transferred into the poly-L-lysine-coated culture flask for continue culture; (2) Cells were shook at $37^{\circ} \mathrm{C}, 250 \mathrm{rpm}$ for $8 \mathrm{~h}$, OPCs were obtained via protocol in scheme $1.4 \mathrm{~mL}$ DMEM culture medium were added into the culture flask, the remaining cells were incubated at $37^{\circ} \mathrm{C}$ for $2 \mathrm{~h}$, followed by being shaken for $8 \mathrm{~h}$ again at $37^{\circ} \mathrm{C}$, $250 \mathrm{rpm}$, finally remanent OPCs were harvested.

When the confluence rate of the purified OPCs was more than $90 \%$, cultured cells were rinsed with PBS, followed by being shaken at $37{ }^{\circ} \mathrm{C}, 180 \mathrm{rpm}$ for $1 \mathrm{~h}$. Cells in the supernatant were collected and seeded in poly-L-lysine-coated 12-well plate for passage culture.

\section{Induced differentiation of OPCs in vitro}

OPCs were directionally differentiated into OLs through being incubated in serum-free medium $(50 \mathrm{~mL}$ DMEM supplement with $1 \times \mathrm{N}-2 \mathrm{Max}, 1 \times \mathrm{B}-27,2 \mathrm{mM}$ glutamine, $40 \mathrm{ng} / \mathrm{mL}$ triiodothyronine (T3), and $100 \mathrm{U} / \mathrm{mL}$ PS) for 3-5 days. DMEM supplement with $1 \times \mathrm{N}-2 \mathrm{Max}, 1 \times$ B-27, 2 mM glutamine, $10 \%$ fetal bovine serum (FBS), and $100 \mathrm{U} / \mathrm{mL}$ PS were applied to induce the differentiation of OPCs into type II astrocytes.

OPCs, OLs, and type II astrocytes were identified with immunocytochemical staining. After being fixed with $4 \%$ paraformaldehyde for 30 min, washed with Immunol Staining Wash Buffer for 3 times, and blocked with QuickBlock ${ }^{\mathrm{TM}}$ reagent for $60 \mathrm{~min}$, they were incubated with primary antibody overnight at $4{ }^{\circ} \mathrm{C}$, respectively. The primary antibodies were as follows: A2B5 (1:1000, Invitrogen, 433110), O4 (1 $\mu \mathrm{g} / \mathrm{Ml}, \mathrm{R} \& \mathrm{D}$ Systems, MAB1326-SP), myelin basic protein (MBP) (1:500, Invitrogen, PA1-46447), and glial fibrillary acidic protein (GFAP) (1:500, Bioss, bs-0199R). After being washed, cells were labeled with secondary antibody including goat anti-mouse IgM (1:1000, Invitrogen, A-21044) or goat anti-rabbit IgG (1:500, Bioss, bs-0295G) for $2 \mathrm{~h}$. Cell nuclei were stained with 4', 6-diamidino-2-phenylindole (DAPI) (Solarbio, C0065). 


\section{Culture and purity identification of $\mathrm{NIH} / 3 \mathrm{~T} 3$ cells}

Cryopreserved NIH/3T3 cells were rapidly thawed, cell supernatant at the density of $1 \times 10^{5}$ cells/mL was seeded into 24-well plate and cultured in DMEM culture medium. When the cell confluence rate reached $85 \%$, the purity of NIH/3T3 cells were evaluated by immunocytochemical staining using anti-vimentin monoclonal antibody (Beyotime, AF1975).

\section{Construction, extraction and verification of pDNA}

The cDNA gene sequences of Olig 2 (NM_016967.2), Nkx 6.2 (NM_183248.3) and Sox 10 (NM_011437.1) were gained from NCBI, their primers were designed on the software Primer 5 (Extended Table 2). After being treated with EcoR I and Xho I, the digested PCR products were respectively inserted into the pEGFP-N1 vector (Extended Fig. 1) to generate the recombinant plasmid pEGFP-N1-Olig 2, pEGFP-N1-Nkx 6.2, and pEGFP-N1-Sox 10.

pDNA molecules were transformed into Trans $5 \alpha$ chemically competent cells, followed by being cultured on Luria-Bertani (LB) broth supplemented with $100 \mu \mathrm{g} / \mathrm{mL}$ kanamycin. Positive bacteria were identified via agarose gel electrophoresis. Extraction of pDNA was carried out according to the instructions of the Zyppy ${ }^{\mathrm{TM}}$ Plasmid Miniprep Kit (ZYMO RESEARCH, D4020). The concentration of pDNA was determined by Microvolume UV-Vis Spectrophotometer (Nano Drop One; Thermo Fisher Scientific).

pDNA molecules were digested with EcoR I and Xho I at $37^{\circ} \mathrm{C}$ for $2.5 \mathrm{~h}$ (Extended Table 3). The digested products were electrophoresed routinely on $1 \%$ agarose horizontal slab gel which contained $2 \mu \mathrm{L}$ Goldview II (Solarbio, G8142), after running for $30 \mathrm{~min}$ at $100 \mathrm{~V}$ and $90 \mathrm{~mA}$, the gel was analyzed by Gel Imaging Analysis System (721BR14799, BIO-RAD).

\section{Cell transfection}

When the confluence rate of NIH/3T3 cells reached over $85 \%$, they were transfected with Olig 2-encoding pDNA molecules (Extended Table 4), which were delivered by Lipofectamine 2000 (Invitrogen, 1690147), Lipofectamine LTX (Invitrogen, 1857395), or Poly-MAG (Chemicell, 9004) with the synergetic action of external magnetic field (Being provided by 96-well MagnetoFACTOR plate (Chemicell), the magnetic force is 280 mTesla) according to the manufacturer's instruction, respectively. After being cultured for $48 \mathrm{~h}$, the transfected efficiencies were calculated based on the percentage of $\mathrm{EGFP}^{+}$cells. 
After being cultured for $48 \mathrm{~h}$, the cytotoxicity resulted from different vector-mediated transfection was detected by LDH assay. The activity of LDH was determined according to the specification of LDH-Cytotoxicity Assay Kit (Beyotime, C0017). Cytotoxicity was evaluated based on the absorbance values which were measured at $490 \mathrm{~nm}$ and $650 \mathrm{~nm}$ using Microplate Absorbance Spectrophotometer (xMark, Bio-Rad).

\section{Determining the optimal concentration of G418 for cell screening}

$\mathrm{NIH} / 3 \mathrm{~T} 3$ cells were seeded into 24-well culture plate. $0 \mathrm{mg} / \mathrm{mL}, 0.1 \mathrm{mg} / \mathrm{mL}, 0.2 \mathrm{mg} / \mathrm{mL}, 0.3$ $\mathrm{mg} / \mathrm{mL}, 0.4 \mathrm{mg} / \mathrm{mL}, 0.5 \mathrm{mg} / \mathrm{mL}, 0.6 \mathrm{mg} / \mathrm{mL}, 0.7 \mathrm{mg} / \mathrm{mL}, 0.8 \mathrm{mg} / \mathrm{mL}, 0.9 \mathrm{mg} / \mathrm{mL}, 1 \mathrm{mg} / \mathrm{mL}$, or $1.1 \mathrm{mg} / \mathrm{mL} \mathrm{G} 418$ was applied to treat cells, respectively. Culture medium supplemented with G418 was changed every third day, after being cultured for 10-14 days, the survival curve of cells was drew to determine the optimal concentration of G418 for screening $\mathrm{EGFP}^{+}$cells.

\section{Poly-MAG-mediated transfection in NIH/3T3 cells}

NIH/3T3 cells were seeded into poly-L-lysine-pre-coated 96-well plate, when the cell confluence rate reached about $80 \%$, they were transfected with different pDNA molecules as follows: (1) pEGFP-N1-Olig 2; (2) pEGFP-N1-Nkx 6.2; (3) pEGFP-N1-Sox 10; (4) pEGFP-N1-Olig 2 and pEGFP-N1-Nkx 6.2; (5) pEGFP-N1-Nkx 6.2 and pEGFP-N1-Sox 10; (6) pEGFP-N1-Olig 2 and pEGFP-N1-Sox 10; (7) pEGFP-N1-Olig 2, pEGFP-N1-Nkx 6.2, and pEGFP-N1-Sox; (8) control group (without pDNA). In brief, $0.2 \mu \mathrm{g}$ pDNA was diluted with 25 $\mu \mathrm{L}_{\text {Opti-MEM }}{ }^{\circledast}$ Medium in $1.5 \mathrm{~mL}$ tube, $0.2 \mu \mathrm{g}$ Poly-MAG was added later, the total volume of mixture was adjusted to $100 \mu \mathrm{L}$ via supplementing Opti-MEM. Then the mixture was dropped on NIH/3T3 cells, the plate was put on the 96-well MagnetoFACTOR plate, 20 min later, the magnetic plate was withdrew, NIH/3T3 cells were cultured in the mixture for $6 \mathrm{~h}$, finally the mixture was substituted with OPC proliferation medium.

After being cultured for $48 \mathrm{~h}$, the transfection efficiency was assessed based on the percentage of $\mathrm{EGFP}^{+}$cells. These cells were digested with trypsin, resuspended with OPC proliferation medium supplemented with $1 \mathrm{mg} / \mathrm{mL} \mathrm{G418}$, and seeded into poly-L-lysine-coated 24-well plate for being cultured for 14 days, then the remaining living cells were identified with immunocytochemical staining, RT-PCR, and Western Blot.

\section{Identification of iOPCs}

Immunocytochemical staining Immunocytochemical staining for A2B5, O4, MBP, and 
GFAP were performed to identify the type of reprogrammed cells. The protocol was same as stated in methods 2.3. The primary antibodies and the secondary antibodies were listed in Extended Table 5.

qPCR The total RNA molecules were extracted from mouse primary OPCs, iOPCs, and NIH/3T3 cells using Quick-RNA ${ }^{\mathrm{TM}}$ MiniPrep Kit (Zymoresearch, R1054), respectively. Then the first cDNAs were synthesized using the ReverAid FirstStrand cDNA Synthesis Kit (Thermo, K1622) (Extended Table 6). The designed primers for RT-PCR were synthesized by the Beijing Huada Gene Co., Ltd (Extended Table 7). Following the instruction of QuantiNova SYBR Green PCR kit (QIAGEN, 208054) (Extended Table 8), PCR was carried out for 39 cycles $\left(94{ }^{\circ} \mathrm{C}\right.$ for 45 $\mathrm{s}, 60{ }^{\circ} \mathrm{C}$ for $45 \mathrm{~s}$, and $72{ }^{\circ} \mathrm{C}$ for $60 \mathrm{~s}$ ) and a final extension $\left(72{ }^{\circ} \mathrm{C}\right.$ for $\left.10 \mathrm{~min}\right)$. Melting curve analysis was applied to validate the relative expression quantities of marker genes.

Western Blot Mouse primary OPCs, iOPCs, and NIH/3T3 cells were harvested. Bicinchoninic acid (BCA) method was applied to quantitate protein concentration following the instruction of total protein extraction kit (Solarbio, BC3710-50T). Western Blot was performed as routine protocol, except that the primary antibodies were $3 \mu \mathrm{g} / \mathrm{mL}$ A2B5 mouse monoclonal antibodies and $\beta$-Actin mouse monoclonal antibodies (1:1 000, Beyotime, AF0003), the secondary antibodies were Alexa Fluor 488-marked goat anti-mouse IgG secondary antibodies (1:1000, Beyotime, A0428) and goat anti-mouse IgM secondary antibodies (1:1000, Invitrogen, A21044). Nitrocellulose membranes were developed using Immobilon Western Chemiluminescent HRP substrate kit (Millipore, 1825001).

\section{Proliferation of iOPCs in vitro}

iOPCs were incubated in OPC proliferation medium supplemented with $0 \mu \mathrm{M}, 0.5 \mu \mathrm{M}, 1 \mu \mathrm{M}$, $1.5 \mu \mathrm{M}, 2 \mu \mathrm{M}$, or $2.5 \mu \mathrm{M}$ HAL for 3 days, then their morphological characteristics and growth status were observed. MTT cell proliferation and cytotoxicity assay kit (Solarbio, M1020) was used to detect the proliferation rate of iOPCs.

\section{Differentiation of iOPCs in vitro}

$0.4 \times 10^{4}$ cells $/ \mathrm{mL}$ iOPCs were seeded into 24 -well plate, different media as stated in methods 2.3 were applied to induce the differentiation of iOPCs. After being cultured for 3-5 days, the differentiated state, morphology, size, and growth status of cells were observed. Immunocytochemical stainings of special markers (Extended Table 5) were used to identify the 
types of differentiated cells. The total RNA molecules were extracted from these cells, the relative expression quantities of marker genes were measured with qPCR.

\section{Statistical analyses}

The experiments were totally repeated for 3 times with 3 repetitions for each group, the data were expressed as 'mean \pm standard deviation'. Data were performed the analysis of variance (ANOVA) with GraphPAD and SPASS software (IBM SPSS Statistics 20), One-Way-ANOVA was applied to analyze the differences between groups of data, and least significant difference (LSD) test was used to perform the multiple comparisons of data.

\section{Results}

\section{Effects of tissue origin, trypsin, and chicken serum on isolation and culture of mouse OPCs} in vitro

After being cultured for 7-9 days, cells isolated from cerebral cortex were obviously separated into two layers: (1) cells in upper layer were mainly OPCs, they were round or oval, most of them had two protrusions, a few of cells has three protrusions; (2) astrocytes with larger size and being contacted with each other were found in the lower layer (Extended Fig. 2I, II). But compared with 1 day old newborn mouse, cells isolated from mouse embryo at the gestational age of 18.5 days were easier to form the distinct layering and exerted more rapid cell proliferation.

Cells isolated with $0.125 \%$ trypsin and $0.25 \%$ chicken serum were uniformly distributed on astrocytes, they appeared higher-density and good growth status (Extended Fig. 2Ib, Ilb). $4 \%$ chicken serum had adverse effect on the digestion action of trypsin. When $1 \%$ chicken serum was added into $0.125 \%$ trypsin (Extended Fig. 2Ic, IIc) or $0.25 \%$ trypsin (Extended Fig. 2Ig, IIg), although layering between OPCs and astrocytes was existed, sparse distribution and less quantity of OPCs were found, similar results occurred in $0.25 \%$ trypsin and $0.25 \%$ chicken serum treatment group (Extended Fig. 2If, IIf). Cells isolated via mechanical pipetting had no obvious layering (Extended Fig. 2II, Fig. 1I). As shown in Fig. 1I, the statistical analysis on the total number of isolated OPCs also confirmed these phenomena.

In addition, Compared with digestion only by trypsin, the supplement of chicken serum could significantly increase the survival rate of cells $(P<0.01)$ (Fig. 1II). Therefore, the optimal 
combination of $0.125 \%$ trypsin and $0.25 \%$ chicken serum was recommended to digest the cerebral cortex of mouse embryo at the gestational age of 18.5 days to harvest primary OPCs.

\section{Effects of different purification protocols on isolation efficiency of mouse OPCs in vitro}

As shown in Extended Fig. 2III, for the same tissue, the density of purified OPCs in scheme 2 was obvious higher than that in scheme 1 . In the same scheme, compared with 1 day old newborn mice, more OPCs were purified from cells which were isolated from embryos at the gestational age of 18.5 days. The statistical analysis on the total number of purified OPCs also confirmed these phenomena (Fig. 1III). Furthermore, the cell survival rate in scheme 2 was significantly higher than that in scheme $1(P<0.01)$. Regardless of the tissue sources, no significant difference was observed in the survival rate of purified OPCs in scheme $2(P>0.05)$ (Fig. 1IV).

The purified $\mathrm{A} 2 \mathrm{~B} 5^{+}$OPCs were round or oval, most of them were bipolar, tripolar morphology was existed only very few cells (Fig. 1V). For cells derived from the same kind of tissue, the rate of $\mathrm{A} 2 \mathrm{~B} 5^{+}$OPCs purified with scheme 2 were significantly higher than that in scheme $1(P<0.01)$ (Fig. 1VI). Therefore, the modified scheme 2 was suitable for the purification of mouse primary OPCs.

\section{The induced differentiation in vitro of mouse OPCs}

Mouse OPCs could proliferate in OPC proliferation medium with maintaining the originally morphological characteristics (Fig. 2Ia). They also could be differentiated into OLs in serum-free medium supplemented with T3 and into type II astrocytes in the presence of serum. Compared with OPCs, the protrusions of OLs obviously became more and longer, most of them would contact with each other, and the size of cell body increased (Fig. 2Ib). Type II astrocytes had typically star-like morphology, many longer protrusions with branches were extended from bigger cell body, which formed a spider-web-like structure (Fig. 2Ic).

OPCs, OLs, and type II astrocytes were positive for A2B5, MBP, and GFAP, respectively (Fig. 2II). OPC proliferation medium, serum-free induced differentiation medium supplemented with T3, and induced differentiation medium with serum could significantly increase the percentage of $\mathrm{A}^{2} \mathrm{B5}^{+}$cells (Fig. $2 \mathrm{IIIa}$ ), $\mathrm{O}^{+}$cells and $\mathrm{MBP}^{+}$cells (Fig. $2 \mathrm{IIIb}$ ), and $\mathrm{GFAP}^{+}$cells (Fig. 2IIIc), respectively $(P<0.01)$. Therefore, these isolated and purified mouse primary OPCs had the potentials to be differentiated into OLs and type II astrocytes.

In vitro culture, morphological observation, and immunocytochemical staining of NIH/3T3 
cells

NIH/3T3 cells showed good growth status, uniform shape, spindle-shaped appearance, and faster proliferation. The cell confluence rate would $50 \%$ (Extended Fig. 3a), $70 \%$ (Extended Fig. 3b), and above $90 \%$ (Extended Fig. 3c) after 2 days, 3 days, and 5 days, respectively. More than $99 \%$ NIH/3T3 cells were vimentin-positive (Extended Fig. 3d-f), so they could be used for further studies.

\section{Extraction and identification of pDNA}

According to results of agarose gel electrophoresis, the positive bacterium suspensions were selected to extract plasmids (Extended Fig. 4a). The concentration and purity of pDNA met the test requirements (Extended Table 9). After being digested with Xho I and EcoR I, the electrophoretic bands of target DNA fragments were bright, and the size of these fragments were consistent with the expected results (Extended Fig. 4b), which indicated that pDNA molecules were successfully constructed.

\section{Effects of different vectors on transfection of Olig 2-encoding pDNA in NIH/3T3 cells}

When $3 \mu \mathrm{g} / \mathrm{mL}$ Olig 2-encoding pNDA was delivered by Lipofectamine 2000, the efficiency of $7.5 \mu \mathrm{g} / \mathrm{mL}$ Lipofectamine 2000-mediated transfection was highest (Fig. 3a). No significant difference was observed in the transfection efficiency of $2 \mu \mathrm{g} / \mathrm{mL}$ pDNA between $7.5 \mu \mathrm{g} / \mathrm{mL}$ and 5 $\mu \mathrm{g} / \mathrm{mL}$ Lipofectamine LTX treatment groups $(P>0.05)$, but they were significantly higher than that of $2.5 \mu \mathrm{g} / \mathrm{mL}$ Lipofectamine LTX treatment group $(P<0.01)$ (Fig. 3b). The efficiency of $2 \mu \mathrm{g} / \mathrm{mL}$ Poly-MAG-mediated transfection reached $70.81 \pm 3.53 \%$, which was significantly higher than that in other Poly-MAG treatment groups $(P<0.01)$ (Fig. 3c). Compared with the optimum transfection efficiencies of these three kinds of non-viral vectors, no significant difference was observed ( $P>0.05$ ) (Fig. 3d-e), however, in these treatment groups, the cytotoxicity in $2 \mu \mathrm{g} / \mathrm{mL}$ Poly-MAG treatment group was significantly lower $(P<0.01)$ (Fig. $3 \mathrm{f}-\mathrm{i}$ ). Therefore, $2 \mu \mathrm{g} / \mathrm{mL}$ Poly-MAG was more suitable for the transfection of $2 \mu \mathrm{g} / \mathrm{mL}$ pEGFP-N1-Olig 2 in NIH/3T3 cells.

\section{Determining the optimal concentration of G418 for cell screening}

With the increasing concentration of G418, the number of NIH/3T3 cells was decreased gradually after being cultured for 14 days (Fig. 4a-j). When cells were treated with $1 \mathrm{mg} / \mathrm{mL} \mathrm{G418}$ for 14 days, almost all cells died (Fig. 4k). If the concentration of G418 was increased to 1.1 $\mathrm{mg} / \mathrm{mL}$, all cells died (Fig. 41). Results which were generated from counting the remaining cells 
also confirmed these morphological characters (Fig. $4 \mathrm{~m}$ ). Therefore, $1.1 \mathrm{mg} / \mathrm{mL}$ G418 was suitable for screening positive NIH/3T3 cells with successful transfection of pDNA.

\section{Transfection efficiency of Poly-MAG-delivered pDNA in NIH/3T3 cells}

As shown in Fig. 4n-v, no significant difference in the percentage of $\mathrm{EGFP}^{+}$cells was observed among single (Olig 2, Nkx 6.2, or Sox 10), two (Olig 2 and Nkx 6.2, Nkx 6.2 and Sox 10, or Olig 2 and Sox 10), and three (Olig 2, Nkx 6.2, and Sox 10) kinds of transcription factors treatment groups $(P>0.05)$, which indicated that the efficiency of Poly-MAG-mediated transfection was independent of the types of these transcription factors.

\section{Generation and identification of iOPCs}

Ectopic expression of Olig 2, Nkx 6.2, or Sox 10 was not enough to reprogram NIH/3T3 cells into A2B5 ${ }^{+}$iOPCs (Fig. 5a). Only 1 to $2 \mathrm{~A}^{2} \mathrm{~B}^{+}$cells were found in Olig 2 and $\mathrm{Nkx} 6.2$, Nkx 6.2 and Sox 10, or Olig 2 and Sox 10 treatment groups, the reprogramming efficiencies were extremely low (Fig. 5b). However, when Olig 2, Nkx 6.2, and Sox 10 were overexpressed together in NIH/3T3 cells, EGFP ${ }^{+}$cells expressed A2B5 (Fig. 5c), which suggested that the synergistic actions of Olig 2, Nkx 6.2, and Sox 10 could reprogram NIH/3T3 cells into iOPCs.

Compared with NIH/3T3 cells, the relative expression quantities of platelet-derived growth factor receptor $\alpha(P D G F R \alpha), S 100 \beta$, neural/glial antigen 2 (NG2), and Olig 2 mRNA in primary OPCs and iOPCs were significantly increased $(P<0.01)$, and the mRNA levels of these genes in primary OPCs was higher than that in iOPCs, respectively $(P<0.05)$. However, the relative expression quantities of Col5al and Collal in primary OPCs and iOPCs were significantly lower than that in fibroblasts $(P<0.01)$ (Fig. 5d). Therefore, the forced expressions of Olig 2, Nkx 6.2, and Sox 10 could attenuate the expressions of fibroblast-related genes and enhance the expressions of OPC-associated genes in NIH/3T3 cells.

As shown in Fig. 5e-f, there was no significant difference in the level of A2B5 protein between primary OPCs and iOPCs $(P>0.05)$. The expression level of A2B5 protein in iOPCs was significantly higher than that in NIH/3T3 cells $(P<0.01)$. Therefore, these generated iOPCs were similar to primary OPCs in the protein expression of special marker A2B5.

\section{Proliferation of iOPCs}

When the concentration of HAL was $1 \mu \mathrm{M}$, the number of iOPCs was obviously more than that in other treatment groups and control group (Extended Fig. 5a-f). Compared with control 
group, the cell proliferation rates were elevated in these treatment groups. Especially, the proliferation rate of iOPCs in $1 \mu \mathrm{M}$ HAL treatment group was significantly higher than that in control group $(P<0.01)$, it was increased by $43.27 \pm 2.36 \%$ (Extended Fig. $5 \mathrm{~g}$ ). Therefore, $1 \mu \mathrm{M}$ HAL was suitable for promoting the proliferation of iOPCs in vitro.

\section{Induced differentiation of iOPCs in vitro}

After being cultured in OPC proliferation medium for 3-5 days, iOPCs maintained the typical OPC-like morphological characteristics (Fig. 6a). Just like the purified primary OPCs, iOPCs could also be differentiated into OLs under serum-free defined culture medium supplemented with T3 (Fig. 6b), and into type II astrocytes in the presence of FBS (Fig. 6c). These iOPC-derived OLs and type II astrocytes had similar morphological characteristics of the corresponding innate cells in vivo and primary OPC-derived cells.

iOPCs, iOPC-derived OLs, and iOPC-derived type II astrocytes were A2B5 ${ }^{+}$(Fig. 6d), $\mathrm{MBP}^{+}$ (Fig. 6e), and $\mathrm{GFAP}^{+}$(Fig. 6f), respectively. In OPC proliferation culture medium, T3 induction medium, and FBS induction medium, the percentage of $\mathrm{A}_{2} \mathrm{B5}^{+}$cells, $\mathrm{O}^{+}$cells or $\mathrm{MBP}^{+}$cells, and $\mathrm{GFAP}^{+}$cells was significantly higher than that of other kinds of cells, respectively $(P<0.01)$ (Fig. $6 \mathrm{~g}-\mathrm{i})$. Compared with other two kinds of cells, the relative expression quantities of PDGFR $\alpha$ and NG2 in iOPCs, MBP in OLs, and GFAP in type II astrocytes were significantly increased, respectively $(P<0.01)$ (Fig. 6j). Therefore, NIH/3T3 cells could be reprogrammed into A2B5 ${ }^{+}$ iOPCs under the overexpressions of Olig 2, Nkx 6.2, and Sox 10, these iOPCs had dual differentiation potentials, they could be differentiated into OLs and type II astrocytes in vitro.

\section{Discussion}

\section{Effects of trypsin and chicken serum on isolation of OPCs}

OPCs originate from the ventricular zones of the brain and spinal cord, they can migrate throughout the developing CNS before being differentiated into myelin-generating OLs. However, the number of OPCs in vivo is less and they proliferate slowly, demyelinating diseases normally cannot be cured only by endogenous OPC-derived OLs. Transplantation of massive exogenous OPCs may be a therapeutic option for these diseases. Isolation of rat OPCs from CNS tissues has been previously established, but it is still difficult to obtain sufficient and high-purity primary 
OPCs in mouse. With the wide applications of transgenic and knockout mice in studying the myelin-related diseases, it is crucial to develop a simple and high-efficient procedure for the isolation and purification of primary OPCs.

Cerebral cortex is the main source of primary OPCs. Trypsin is usually used to digest tissues for isolating cells, such as skin fibroblasts. Unlike skin, cerebral cortex is softer and easier to be damaged by trypsin. As distinguished from FBS which is normally applied to terminate the digestion of trypsin, chicken serum does not contain inhibitors to trypsin, after being added into trypsin solution, it can provide proteins that protect cells [5], such as chicken blastodermal cells [6] and human induced pluripotent stem cell (iPSC)-derived cardiomyocytes [7]. Our results also showed that $0.125 \%$ trypsin supplemented with $0.25 \%$ chicken serum could increase the number and survival rate of primary OPCs, which was suitable for isolating OPCs from brain cortex.

With the increase of age, myelin regeneration decline and white matter lesions accumulate [8]. In the adult brain, $2-3 \%$ of the cells in the gray matter and $5-8 \%$ of the cells in the white matter are OPCs. Age may affect the isolation efficiency of OPCs. Compared with new-born mouse at the age of 1 day, OPCs could be more easily harvested from cerebral cortex of mouse at the gestational age of 18.5 days, the obvious layering between OPCs and astrocytes presented one day to two days in advance, and the proliferation of OPCs was faster, which was consistent with that reported by Chen et al (2007) [9]. Therefore, the cerebral cortex of mouse embryo at gestational age of 18.5 days was recommended to isolate primary OPCs.

\section{Effects of different purified strategies on isolation of OPCs}

For both experimental and therapeutic purposes, it is essential to obtain highly purified OPCs. Several strategies for purifying OPCs have been implemented, such as immunopanning [10], magnetic activated cell sorting [11], fluorescence-activated cell sorting [12], special factors induced approach [13], differential and density gradient centrifugation, and shaking method. However, these existing methods have many restrictions in practice, particularly in terms of purity, yield, time, and cost. For example, NG2 can be found in other cells besides OPCs [14], PDGFR-AA exists in special phase of OPC lineage [15], OPCs become heterogeneous cell populations with increasing age or under the stimulations of cytokines [16, 17], which impede approaches based on distinctive cell surface markers.

Based on differently adherent properties of glia, shaking method is also applied to purify 
OPCs. However, during the traditional method, the co-incubated cells with obvious two layers were shaken at the speed of 200-260 rpm for $18-20 \mathrm{~h}$ to purify OPCs, leaving astrocytes and fibroblasts on the surface of flask. Although a certain number of OPCs could be harvested, but OPCs were very easily damaged. After being shaken at speed of $250 \mathrm{rpm}$ for about $18 \mathrm{~h}$ in this study, some OPCs were broke down into pieces, and the cell viability was only $60.31 \pm 3.54 \%$, which was consistent with results reported by Medina-Rodríguez et al (2013) [18]. When the traditional shaking process was separated into two steps here, namely, after being shaken for $8 \mathrm{~h}$ at the speed of $250 \mathrm{rpm}$, OPCs in cell suspension were collected, the remaining cells were cultured in incubator for $2 \mathrm{~h}$, followed by being shaken for another about $8 \mathrm{~h}$ for collecting residual OPCs. This kind of interrupted shaking method could not only timely supplement the nutrients, but also replenish $\mathrm{CO}_{2}$ to recover OPCs. Compared with traditional purification method, the cell viability of OPCs was significantly increased $(P<0.01)$, and the purity of generated OPCs reached $97.26 \pm$ $2.63 \%$. Therefore, OPCs could be high-efficiently purified with our optimized shaking scheme.

\section{Induced differentiation of OPCs}

Four distinct stages of OL maturation from OPCs have been identified as following: OPCs, preoligodendrocytes, immature OLs, and myelin-generating OLs [19]. These stages are sophisticatedly regulated by numerous factors. For example, G protein-coupled receptor 56 (GPR56) and miR-7a promoted OPC proliferation [20, 21]; Chd7 protected nonproliferative OPCs from apoptosis [22]; miR-219 and miR-338 promoted the normal differentiation of OPCs into OLs [23]; Glycosphingolipid biosynthesis-promoting taurine could dramatically enhance the maturation of OPCs [24]; Treatment with endothelial progenitor cell (EPC) secretome and even voluntary wheel running could also high-efficiently accelerate myelination [25, 26]. On other hand, myelination was also inhibited by Wnt signaling pathway [27], the constitutional disruption of Pten nuclear localization [28], the inadequate migration of OPCs [29], and so on. The majority of adult OPCs are generally quiescent with limited self-renewal, the cell cycle of them is accelerated as the respond to demyelination-related injuries or diseases. However, approximately $70 \%$ of lesions contained progenitors or premyelinating OLs which are characterized by inability to differentiate into mature cells for the hostile microenvironment [30-32]. Therefore, it is very necessary to study the induced differentiation and maturation of OPCs.

OPCs also could secede from cell cycle and be differentiated into OLs under the action of 
thyroid hormone (TH) [33]. The promoter of $M B P$ gene contains response sequences of thyroid hormone receptor (TR), T3 can bind to TR and up-regulate the expression of MBP [24]. Deletion of TR in vivo would give rise to persistent proliferation of OPCs and the absence of myelin in adult mouse [34]. Excessive TH would decrease the proliferation area of OPCs in CNS. Our results also confirmed that $40 \mathrm{ng} / \mathrm{mL} \mathrm{T3}$ could induce the directional differentiation of OPCs into OLs in vitro. Serum could up-regulate the expression of direct target genes (such as ID1, ID2, and ID3) for bone morphogenetic protein (BMP) in human neural progenitor cells (NPCs), ID genes of rat astrocytes in vitro [35], and the astrocyte-related genes such as angiotensinogen and cathepsin $H$ in human NPCs [36]. We also confirmed that $10 \%$ FBS could contribute to converting OPCs into type II astrocytes in vitro. Therefore, primary OPCs isolated with our modified isolation and purification strategies had bidirectional differentiation potentials, these results were in accordance with that reported by $\mathrm{Hu}$ et al (2011) [37], which laid the foundation for higher-efficiently harvesting OPCs for cell replacement therapy, disease modeling, and so on.

\section{Nanoparticle vector-mediated transfection of pDNA}

Many drawbacks such as higher immunogenicity and cytotoxicity, and potential biosafety hazard, limit viral vectors to be applied in cell therapies. Non-viral transfection reagents have been widely concerned in this field. Poly-MAG is a kind of PEI-coated MIONs with the hydrodynamic diameter of $100 \mathrm{~nm}$, which can bind pDNA molecules via electrostatic adherence. pDNA-carrying Poly-MAG complexes will be endocytosed by cells, then they are captured by lysosome. Abundant amidogen (-NH 2$)$ of PEI can be protonated, many protons are captured by PEI, which results in the increase of $\mathrm{Cl}^{-}$in lysosome, followed by osmotic swelling and rupture of lysosome, then pDNA can be released into cytoplasm, and express in nucleus [38]. Poly-MAG-mediated transfection is affected by many factors, such as the number of pDNA, transfection time, and external magnetic field. It is necessary to screen the optimal conditions for reprogramming NIH/3T3 cells into iOPCs.

NIH/3T3 cells were incubated here with Poly-MAG for 20 min under the synergistic action of exogenous magnetic field, then the 96-well MagnetoFACTOR plate was withdrew. After co-incubation of nanoparticles and cells for $6 \mathrm{~h}$, the transfection solution was replaced by normal culture medium. Albeit no significant difference in the respectively optimum transfection efficiency was observed among Poly-MAG, Lipofectamine 2000, and Lipofectamine LTX 
$(P>0.05)$, cytotoxicity of Poly-MAG was significantly lower than that of these two kinds of liposome vectors $(P<0.01)$. Compared with cationic liposomes, the PEI-coated MIONs have the following advantages in gene transfection: (i) More pDNA molecules can be bound via electrostatic adherence based on larger surface area of nanoparticle and abundant amidogens $\left(-\mathrm{NH}_{2}\right)$ of $\mathrm{PEI}$; (ii) More pDNA-carrying MIONs would be rapidly enriched on cytomembrane under the action of exogenous magnetic field, increasing the transfection efficiency; (iii) MIONs have the desired biocompatibility and low cytotoxicity; (iv) MIONs can protect pDNA from digestion of lysosomal enzymes and DNAase, which enhances the stable expression of target genes. Therefore, PEI-coated MION is a novel, safer, higher efficient non-viral vector, which is more appropriate for mediating the reprogramming of NIH/3T3 cells into iOPCs.

\section{Generation of iOPCs in vitro}

In addition to ESCs [39], iPSCs [40], and autologous bone marrow-derived neural stem cells (NSCs) [41], iOPCs can also generated from easy-to-obtain, autogeneic, and differentiated cells via indirect lineage transformation. After analyzing the functional transcription factors in NPCs and OPCs, Sox 10 was identified as the master switch for determining the fate of iOPCs [1]. The forced expressions of Olig 2, Nkx 6.2, and Sox 10 could reprogram mouse embryonic fibroblasts (MEFs) and mouse lung fibroblasts into iOPCs [2]. The ectopic expressions of Olig 2, Sox 10, and Zfp 536 were sufficient to convert rat embryonic fibroblast into iOPCs [3]. Lee \& Park (2017) found that Olig 2, Nkx 6.2, and Sox 10 were more suitable to reprogram MEFs into iOPCs, however, only a few cells survived and expressed NG2 after MEFs were transfected with Olig 2, Sox 10, and Zfp 536 [4]. Since NIH/3T3 cells were originally established from the primary MEFs,

Olig 2, Nkx 6.2, and Sox 10 were adopted here to reprogram these cells. In order to improve the safety of generated iOPCs, we selected Poly-MAG as transgenic vector, but not viral vectors (such as retroviral vector and lentivirus vector) which were used in reports mentioned above.

Our results shown that the forced expressions of Poly-MAG-delivered Olig 2, Nkx 6.2, and Sox 10 could reprogram NIH/3T3 cells into OPC-like cells, the reprogramming efficiency was $68.37 \pm 2.05 \%$, it was lower than that of retroviral vector-mediated transfection which was reported by Lee \& Park (2017) [4], it might be associated with the applied transgenic vector. However, when virus vectors were applied to deliver pDNA, there was a large potential safety hazard in the clinical applications of iOPCs. Magnetic nanoparticles could efficiently circumvent 
this problem and enhance the safety of iOPCs. During the ectopic expressions of Olig 2, Nkx 6.2, and Sox 10, fibroblast-related genes Col5al and Col1a1 were attenuated, while the expressions of OPC-associated genes $P D G F R \alpha, S 100 \beta, N G 2$, and Olig2 were enhanced, these generated iOPCs had typical morphology characteristics of OPCs and expressed A2B5.

G418, a kind of aminoglycosides, can affect the functions of ribosome via inhibiting transposon genes $\operatorname{Tn} 601$ and $\operatorname{Tn} 5$, followed by blocking the synthesis of protein. It is toxic to both prokaryotic and eukaryotic cells. In order to determine the protocol for cell screening, different concentrations of G418 were applied to treat NIH/3T3 cells. $1.1 \mathrm{mg} / \mathrm{mL} \mathrm{G418} \mathrm{was} \mathrm{adopted} \mathrm{here}$ for screening $\mathrm{EGFP}^{+}$cells.

\section{Proliferation and induced differentiation of iOPCs in vitro}

In order to promote the proliferation of iOPCs, PDGF-AA and FGF are usually supplemented in culture medium, they are mitogens of OPC proliferation. PDGF-AA can active extracellular signal-regulated kinases 1/2 (Erk 1/2), phosphatidylinositol 3-kinase (PI3K), and p38 signaling pathways. FGF can induce the expression of Olig 2 and activate mitogen-activated protein kinase (MAPK) and Erk 1/2 kinase, which promotes the proliferation and migration of OPCs. Fu et al (2007) reported that PDGF and bFGF could enhance the differentiation of NPCs into A2B ${ }^{+}$OPCs [42]. Epidermal growth factor (EGF) is another potent mitogen for OPCs, which can collaborate with PDGF-AA to extend cell division and inhibit their differentiations.

HAL, a typical antipsychotic medication, could increase the number of NSCs, resulting in more progenitors, new neurons, and glia in the brain of adult rat [43]. $1 \mu \mathrm{mol} / \mathrm{L}$ HAL could obviously facilitate the proliferation of iOPCs here, which was coincident with the results reported by Niu et al (2010) [44]. It is widely believed that HAL is an antagonist of dopamine D2 and D3 receptors in CNS. Since dopamine D3 receptor is expressed in OPCs and immatured OLs, dopamine D2 receptor is expressed after the mature of OLs. Therefore, HAL may expedite the proliferation of OPCs via inhibiting dopamine D3 receptor.

Like primary OPCs, iOPCs also could be differentiated into OLs and Type II astrocytes under the induction of $\mathrm{T} 3$ and FBS, respectively. As shown by the immunocytochemical staining assays, the percentage of iOPC-derived OLs was $72.67 \pm 2.52 \%$, and the rate of iOPC-derived type II astrocytes was $75.36 \pm 1.98 \%$, which were lower than that of OPC-derived OLs and type II astrocytes $(>95 \%)$. It might be resulted from the inhomogeneity of reprogramming, which was 
similar to the generation of iPSCs, a few iPSCs were not completely reprogrammed [45].

\section{Conclusions}

In summary, chicken serum and modified shaking method were conducive to isolating and purifying OPCs. PEI-coated MION was a novel, safer, higher efficient non-viral vector for delivering exogenous genes into cells. Forced expressions of Olig 2, Nkx 6.2, and Sox 10 could efficiently convert NIH/3T3 cells into iOPCs, $1 \mu \mathrm{mol} / \mathrm{L}$ HAL contributed to promoting their proliferation. Both primary OPCs and iOPCs had bidirectional differentiation potentials, which provided abundant cell resources for elucidating mechanisms on loss and regeneration of myelin, treating demyelination-related diseases, constructing disease models, developing new drugs, and so on.

\section{Supplementary information}

Extended Fig.1 pEGFP-N1 vector

Extended Fig. 2 Effects of trypsin and chicken serum on isolation and culture of mouse primary OPCs

Extended Fig. 3 Cultured in vitro and immunocytochemical staining of NIH/3T3 cells

Extended Fig. 4 Extraction and identification of pDNA

Extended Fig. 5 Effects of HAL at different concentrations on proliferation of iOPCs in vitro

Extended Table 1 Methods for digestion of cerebral cortex in mouse

Extended Table 2 Primer information of three kinds of transcription factors for PCR

Extended Table 3 Scheme for restriction enzyme digestion of pDNA

Extended Table 4 Scheme for different vector-mediated cell transfection

Extended Table 5 Antibodies for immunocytochemical staining

Extended Table 6 Sampling program for reverse transcription

Extended Table 7 Primer information for RT-PCR

Extended Table 8 RT-PCR reaction system

Extended Table 9 Detection for concentration and purity of pDNA

\section{Abbreviations}

OLs: Oligodendrocytes; OPCs: oligodendrocyte progenitor cells; iOPCs: induced 
oligodendrocyte progenitor cells; HAL: haloperidol; CNS: central nerve system; MIONs: magnetic iron oxide nanoparticles; pDNA: plasmid DNA; PEI: polyethyleneimine; Olig 2: oligodendrocyte lineage transcription factor 2; Nkx 6.2: NK 6 homeobox transcription factor 2; Sox 10: sex-determining region Y-related high-mobility group box 10; EGFP: enhanced green fluorescent protein; PS: penicillin-streptomycin mixed solutions; FGF: fibroblast growth factor; PDGF-AA: platelet derived growth factor AA; T3: triiodothyronine; FBS: fetal bovine serum; GFAP: glial fibrillary acidic protein; DAPI: 4', 6-diamidino-2-phenylindole; LB: Luria-Bertani; LDH: lactic dehydrogenase; LSD: least significant difference; PDGFR $\alpha$ : platelet-derived growth factor receptor $\alpha$; NG2: neural/glial antigen 2; GPR56: G protein-coupled receptor 56; EPC: endothelial progenitor cell; TH: thyroid hormone; TR: thyroid hormone receptor; BMP: bone morphogenetic protein; NPCs: neural progenitor cells; NSCs: neural stem cells; MEFs: mouse embryonic fibroblasts; Erk 1/2: extracellular signal-regulated kinases 1/2; PI3K: phosphatidylinositol 3-kinase; MAPK: mitogen-activated protein kinase; EGF: Epidermal growth factor.

\section{Authors' contributions}

Xiong Xiao, Wenhui Ling, and Yuemin Li made substantial contributions to conception and design; Xiong Xiao, Wenhui Ling, Mingyu Wang, Chunxia Xiong, and Dengfeng Xie had made substantial contributions to acquisition of data; Xiong Xiao, Wenhui Ling, Xinyue Chu, Yunxin Li, and, Yun Huang had made contributions to analysis and interpretation of data; Xiong Xiao, Wenhui Ling, Xiaoyan Qiu, Tong Li, and Yuemin Li had been involved in drafting the manuscript or revising it critically for important intellectual content; The authors read and approved the final manuscript.

\section{Funding}

This work was supported in part by the National Natural Science Foundation of China (31572488), Based and Advanced Research Projects of Chongqing (cstc2017jcyjAX0477), Fundamental Research Funds for the Central Universities (XDJK2020B011), Chongqing Technological Innovation and Application Demonstration for Social and Livelihood Development (cstc2018jscx-msybX0240).

\section{Availability of data and materials}

All data generated or analyzed during this study are included in this published article. 


\section{Ethics approval and consent to participate}

Not applicable.

\section{Consent for publication}

Not applicable.

\section{Competing interests}

The authors declare that they have no competing interests.

\section{Author details}

Department of veterinary medicine, College of Animal Science and Technology, Southwest University, Chongqing 400715, China

\section{References}

1. Wang J, Pol SU, Haberman AK, Wang C, O'Bara MA, Sim FJ. Transcription factor induction of human oligodendrocyte progenitor fate and differentiation. Proc Natl Acad Sci USA. 2014;111:2885-94.

2. Najm FJ, Lager AM, Zaremba A, Wyatt K, Caprariello AV, Factor DC, et al. Transcription factor-mediated reprogramming of fibroblasts to expandable, myelinogenic oligodendrocyte progenitor cells. Nat Biotechnol. $2013 ; 31: 426-33$.

3. Yang N, Zuchero J B, Ahlenius H, Marro S, Ng YH, Vierbuchen T, et al. Generation of oligodendroglial cells by direct lineage conversion. Nat Biotechnol. 2013;31:434-9.

4. Lee EH, Park $\mathrm{CH}$. Comparison of reprogramming methods for generation of induced-oligodendrocyte precursor cells. Biomol Ther. 2017;25:362-6.

5. Tian XH, Kaufman D S. In Methods in Molecular Biology: Basic Cell Culture Protocols (Eds: Helgason CD. Miller CL). Humana Press Inc. Totowa 2005; pp. 149-62.

6. Fraser RA, Carsience RS, Clark ME, Etches RJ, Gibbins AM. Efficient incorporation of transfected blastodermal cells into chimeric chicken embryos. Int J Dev Biol. 1993;37:381-5.

7. Zhang J, Klos M, Wilson GF, Herman AM, Lian X, Raval KK, et al. Extracellular matrix promotes highly efficient cardiac differentiation of human pluripotent stem cells: The matrix sandwich method. Circ Res. 2012;111:1125-36.

8. Habes M, Erus G, Toledo JB, Zhang T, Bryan N, Launer LJ, et al. White matter hyperintensities and imaging patterns of brain ageing in the general population. Brain, 2016. 139(Pt4):1164-79.

9. Chen Y, Balasubramaniyan V, Peng J, Hurlock EC, Tallquist M, Li J, et al. Isolation and culture of rat and 
mouse oligodendrocyte precursor cells. Nat Protoc. 2007;2:1044-51.

10. Emery B, Dugas JC. Purification of oligodendrocyte lineage cells from mouse cortices by immunopanning. Cold Spring Harb Protoc. 2013;2013:854-68.

11. Dincman TA, Beare JE, Ohri SS, Whittemore SR. Isolation of cortical mouse oligodendrocyte precursor cells. J Neurosci Methods. 2012;209:219-26.

12. Djelloul M, Azevedo C, Pomeshchik Y, Hammarberg A, Roybon L. Reporting on methods to generate and purify rodent and human oligodendrocytes from different sources. Stem Cell Res. 2017;20:58-66.

13. Yang J, Cheng X, Shen J, Xie B, Zhao X, Zhang Z, et al. A novel approach for amplification and purification of mouse oligodendrocyte progenitor cells. Front Cell Neurosci. 2016;22:203.

14. Richardson WD, Young KM, Tripathi RB, McKenzie I. NG2-glia as multipotent neural stem cells: fact or fantasy? Neuron. 2011;70:661-73.

15. Cahoy JD, Emery B, Kaushal A, Foo LC, Zamanian JL, Christopherson KS, et al. A transcriptome database for astrocytes, neurons, and oligodendrocytes: a new resource for understanding brain development and function. J Neurosci. 2008;28: 264-78.

16. Spitzer SO, Sitnikov S, Kamen Y, Evans KA, Kronenberg-Versteeg D, Dietmann S, et al. Oligodendrocyte progenitor cells become regionally diverse and heterogeneous with age. Neuron. 2019;101:459-71.

17. Lentferink DH, Jongsma JM, Werkman I, Baron W. Grey matter OPCs are less mature and less sensitive to IFN $\gamma$ than white matter OPCs: consequences for remyelination. Sci Rep. 2018;8:2113.

18. Medina-Rodríguez EM, Arenzana FJ, Bribián A, de Castro F. Protocol to isolate a large amount of functional oligodendrocyte precursor cells from the cerebral cortex of adult mice and humans. PLoS One. 2013;8:e81620.

19. Flores-Obando RE, Freidin MM, Abrams CK. Rapid and specific immunomagnetic isolation of mouse primary oligodendrocytes. J Vis Exp. 2018;135:57543.

20. Giera S, Luo R, Ying Y, Ackerman SD, Jeong SJ, Stoveken HM, et al. Microglial transglutaminase-2 drives myelination and myelin repair via GPR56/ADGRG1 in oligodendrocyte precursor cells. Elife. 2018;7.pii:e33385.

21. Zhao X, Wu J, Zheng M, Gao F, Ju G. Specification and maintenance of oligodendrocyte precursor cells from neural progenitor cells: Involvement of microRNA-7a. Mol Biol Cell. 2012;23:2867-78.

22. Marie C, Clavairoly A, Frah M, Hmidan H, Yan J, Zhao C, et al. Oligodendrocyte precursor survival and differentiation requires chromatin remodeling by Chd7 and Chd8. Proc Natl Acad Sci USA. 
2018;115:E8246-55.

23. Zhao X, He X, Han X, Yu Y, Ye F, Chen Y, et al. MicroRNA-mediated control of oligodendrocyte differentiation. Neuron. 2010;65:612-26.

24. Beyer BA, Fang M, Sadrian B, Montenegro-Burke JR, Plaisted WC, Kok BPC, et al. Metabolomics-based discovery of a metabolite that enhances oligodendrocyte maturation. Nat Chem Biol. 2018;14:22-8.

25. Maki T, Morancho A, Martinez-San Segundo P, Hayakawa K, Takase H, Liang AC, et al. Endothelial progenitor cell secretome and oligovascular repair in a mouse model of prolonged cerebral hypoperfusion. Stroke. 2018; 49:1003-10.

26. Zheng J, Sun X, Ma C, Li BM, Luo F. Voluntary wheel running promotes myelination in the motor cortex through Wnt signaling in mice. Mol Brain. 2019;12:85.

27. Fancy SP, Baranzini SE, Zhao C, Yuk DI, Irvine KA, Kaing S, et al. Dysregulation of the Wnt pathway inhibits timely myelination and remyelination in the mammalian CNS. Genes Dev. 2009;23:1571-85.

28. Lee H, Thacker S, Sarn N, Dutta R, Eng C. Constitutional mislocalization of Pten drives precocious maturation in oligodendrocytes and aberrant myelination in model of autism spectrum disorder. Transl Psychiatry. 2019;9:13.

29. O'Meara RW, Cummings SE, Michalski JP, Kothary R. A new in vitro mouse oligodendrocyte precursor cell migration assay reveals a role for integrin-linked kinase in cell motility. BMC Neurosci. 2016;17:7.

30. Huang Y, Dreyfus CF. The role of growth factors as a therapeutic approach to demyelinating disease. Exp Neurol. 2016;283:531-40.

31. Piatek P, Namiecinska M, Domowicz M, Przygodzka P, Wieczorek M, Michlewska S, et al. MS CD49d+ CD154+ lymphocytes reprogram oligodendrocytes into immune reactive cells affecting CNS regeneration. Cells. 2019a;8:pii:E1508.

32. Piatek P, Namiecinska M, Domowicz M, Wieczorek M, Michlewska S, Matysiak M, et al. Multiple Sclerosis CD49d+CD154+ as myelin-specific lymphocytes induced during remyelination. Cells. 2019b;9:pii:E15.

33. Franco P, Silvestroff L, Soto E, Pasquini JM. Thyroid hormones promote differentiation of oligodendrocyte progenitor cells and improve remyelination after cuprizone-induced demyelination. Exp Neurol. 2008;212:458-67.

34. Baas D, Legrand C, Samarut J, Flamant F. Persistence of oligodendrocyte precursor cells and altered myelination in optic nerve associated to retina degeneration in mice devoid of all thyroid hormone receptors. Proc Natl Acad Sci USA. 2002;99: 2907-11. 
35. Obayashi S, Tabunoki H, Kim S, Satoh J. Gene expression profiling of human neural progenitor cells following the serum-induced astrocyte differentiation. Cell Mol Neurobiol. 2009;29:423-38.

36. Brguljan P, Turk V, Nina C, Brzin J, Krizaj I, Popovic T. Human brain cathepsin H as a neuropeptide and bradykinin metabolizing enzyme. Peptides. 2003;24:1977-84.

37. Hu J, Wang Y, Zhou J, Chen CJ, Wang FC, Li XW, et al. Differential gene expression in oligodendrocyte progenitor cells, oligodendrocytes and type II astrocytes. Tohoku J Exp Med. 2011;223:161-76.

38. Arsianti M, Lim M, Cpmarquis, Amal R. Polyethylenimine based magnetic iron-oxide vector: the effect of vector component assembly on cellular entry mechanism, intracellular localization, and cellular viability. Biomacromolecules. 2010;11:2521-31.

39. Manley NC, Priest CA, Denham J, Wirth ED 3rd, Lebkowski JS. Human embryonic stem cell-derived oligodendrocyte progenitor cells: preclinical efficacy and safety in cervical spinal cord injury. Stem Cells Transl Med. 2017;6:1917-29.

40. Yamashita T, Miyamoto Y, Bando Y, Ono T, Kobayashi S, Doi A, et al. Differentiation of oligodendrocyte progenitor cells from dissociated monolayer and feeder-free cultured pluripotent stem cells. PLoS One. 2017;2:e0171947.

41. Zhang Y, Lu XY, Casella G, Tian J, Ye ZQ, Yang T, et al. Generation of oligodendrocyte progenitor cells from mouse bone marrow cells. Front Cell Neurosci. 2019;13:247.

42. Fu SL, Hu JG, Li Y, Wang YX, Jin JQ, Xui XM, et al. A simplified method for generating oligodendrocyte progenitor cells from neural precursor cells isolated from the E16 rat spinal cord. Acta Neurobiol Exp (Wars). $2007 ; 67: 367-77$.

43. Kippin TE, Kapur S, van der Kooy D. Dopamine specifically inhibits forebrain neural stem cell proliferation, suggesting a novel effect of antipsychotic drugs. J Neurosci. 2005;25:5815-23.

44. Niu J, Mei F, Li N, Wang H, Li X, Kong J, et al. Haloperidol promotes proliferation but inhibits differentiation in rat oligodendrocyte progenitor cell cultures. Biochem Cell Biol. 2010;88: 611-20.

45. Meissner A, Wernig M, Jaenisch R. Direct reprogramming of genetically unmodified fibroblasts into pluripotent stem cells. Nat Biotechnol. 2007;25:1177-81. 


\section{Figures}
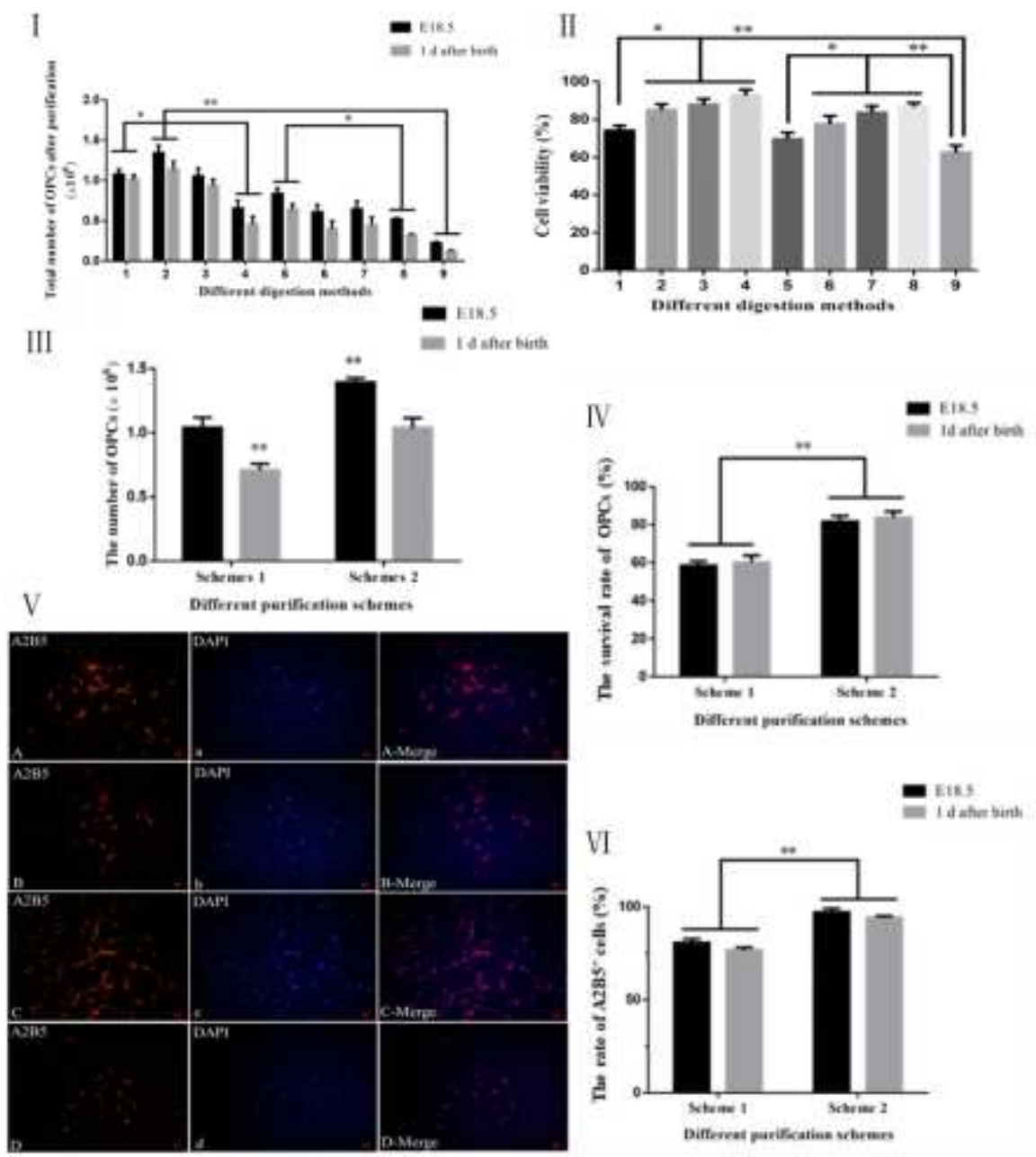

\section{Figure 1}

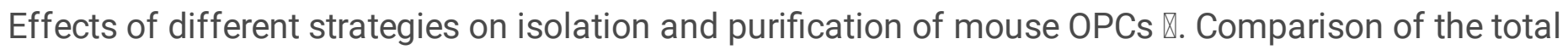
number of primary OPCs isolated with different digestion methods. . Comparison of cell viability of primary OPCs isolated with different digestion methods. Treatment groups 1 to 9 in $\nabla$ and $\nabla$ were

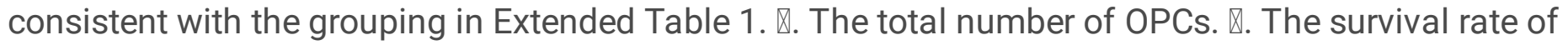
OPCs. $\triangle$. Immunocytochemical staining of A2B5. The means of a to $d$ was same as notes in Extended Fig. $1 \rrbracket, B a r=20 \mu \mathrm{m}$. $\otimes$. The rate of $A 2 B 5+$ cells. ${ }^{*} P<0.05, * \star P<0.01$. 


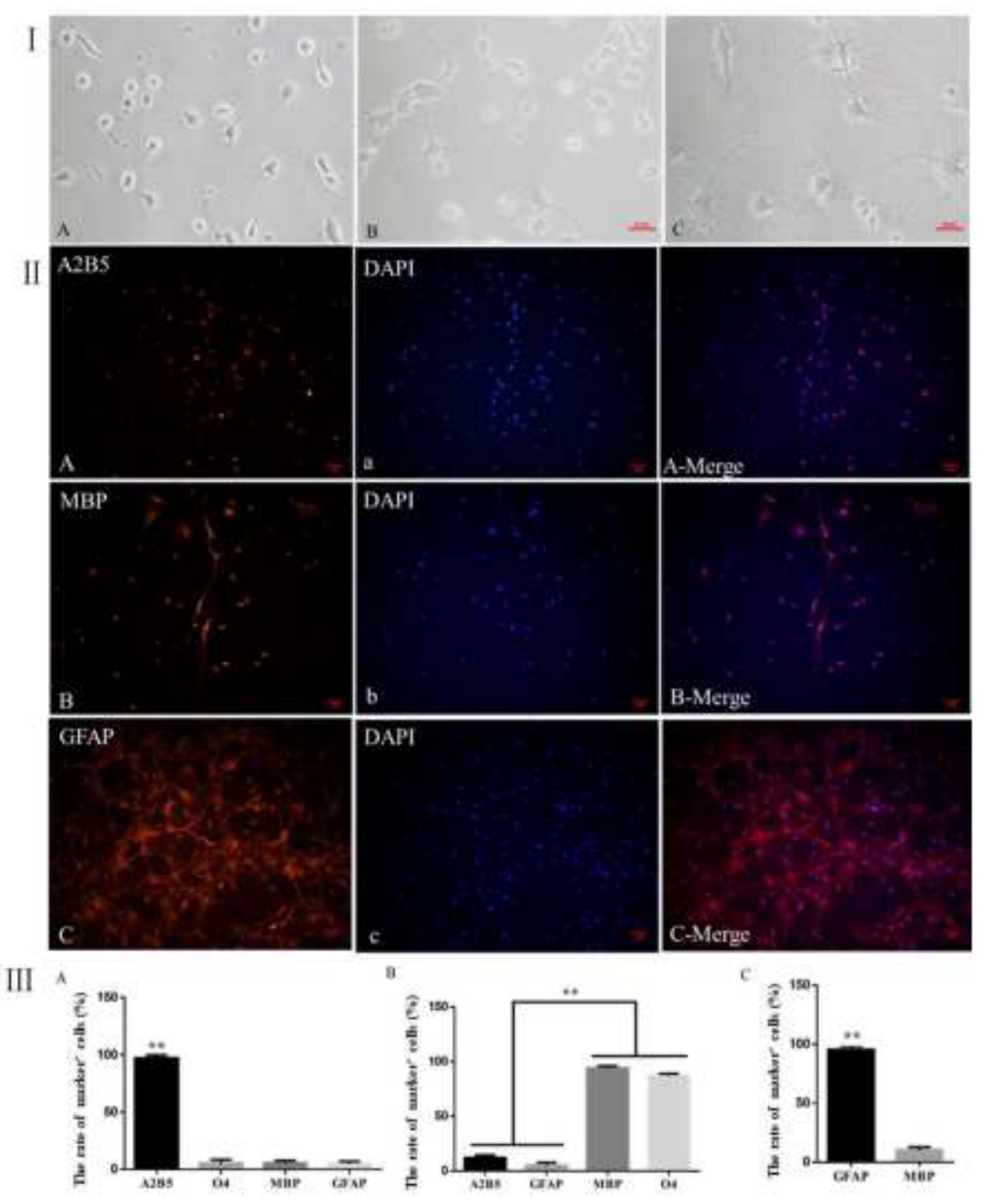

\section{Figure 2}

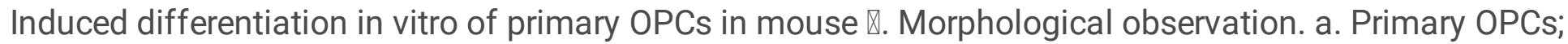
b. OLs derived from primary OPCs after being induced with T3; c. Type $\otimes$ astrocytes differentiated from primary OPCs after being induced with serum. Bar=20 $\mu \mathrm{m}$. $\otimes$. Immunocytochemical staining. Bar=25 $\mu \mathrm{m}$.

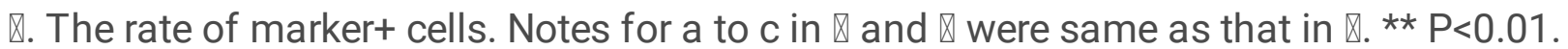



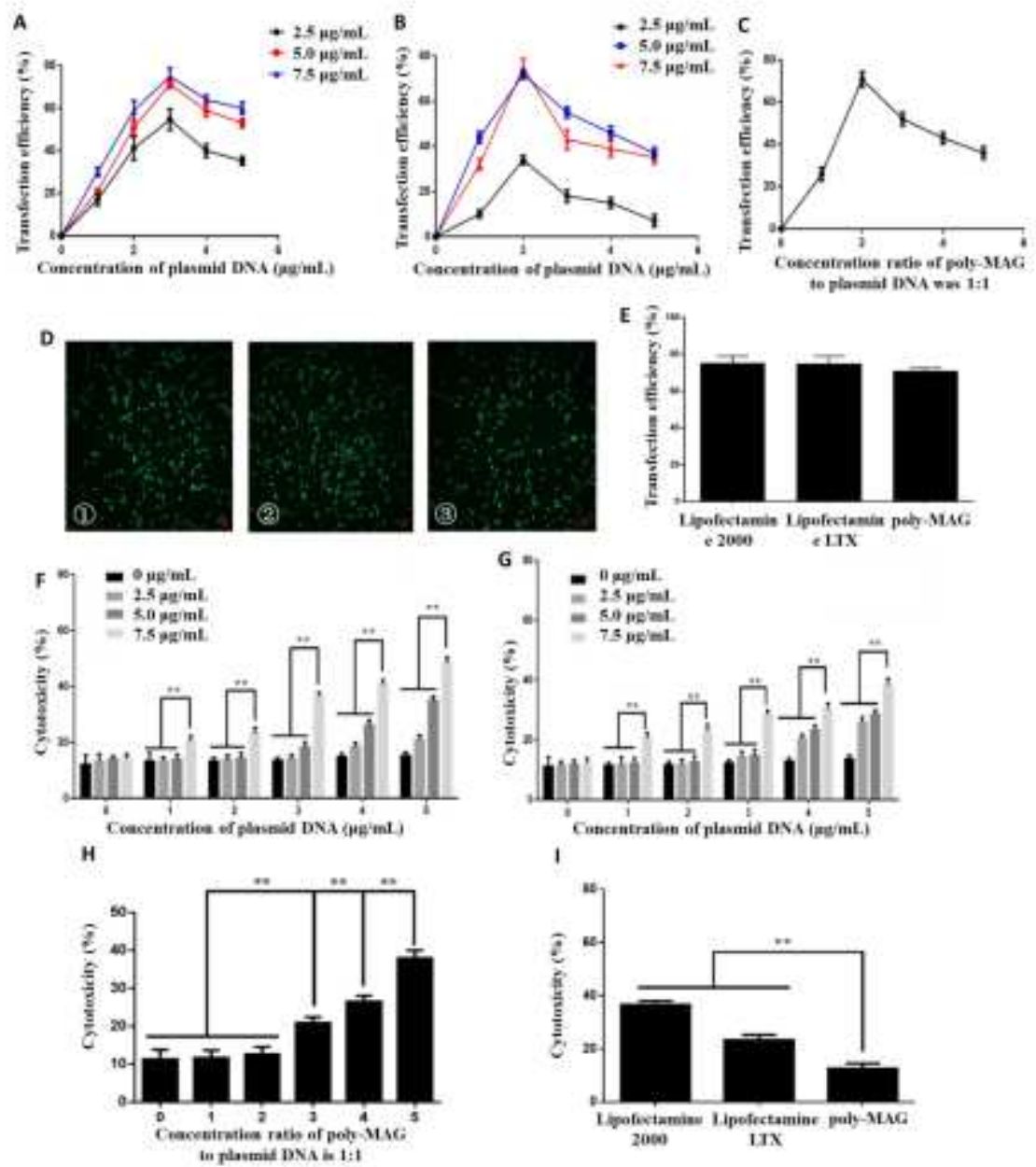

Figure 3

Effects of different vectors on transfection of Olig 2-encoding pDNA in NIH/3T3 cells a-c. Transfection efficiency of different vector-delivered pDNA at different concentration (a. Lipofectamine 2000; b. Lipofectamine LTX; c. Poly-MAG); d-e. The optimal efficiency of different vector-mediated transfection (ख囚. EGFP+ NIH/3T3 cells; $₫ .5 \mu \mathrm{g} / \mathrm{mL}$ Lipofectamine 2000 combined with $3 \mu \mathrm{g} / \mathrm{mL} \mathrm{pDNA}$; $\nabla 5 \mathrm{\mu g} / \mathrm{mL}$ Lipofectamine LTX combined with $2 \mu \mathrm{g} / \mathrm{mL}$ pDNA; $\bigotimes$. $2 \mu \mathrm{g} / \mathrm{mL}$ Poly-MAG combined with $2 \mu \mathrm{g} / \mathrm{mL}$ pDNA. $B a r=25 \mu \mathrm{m} ; \mathrm{E}$. Comparation of the optimal transfection efficiency); f-i. Cytotoxicity resulted from different vector-mediated transfection (f. Lipofectamine 2000; g. Lipofectamine LTX; h. Poly-MAG; i. Comparation of cytotoxicity of each kind of vector with optimal transfection efficiency). ${ }^{\star \star} P<0.01$. 

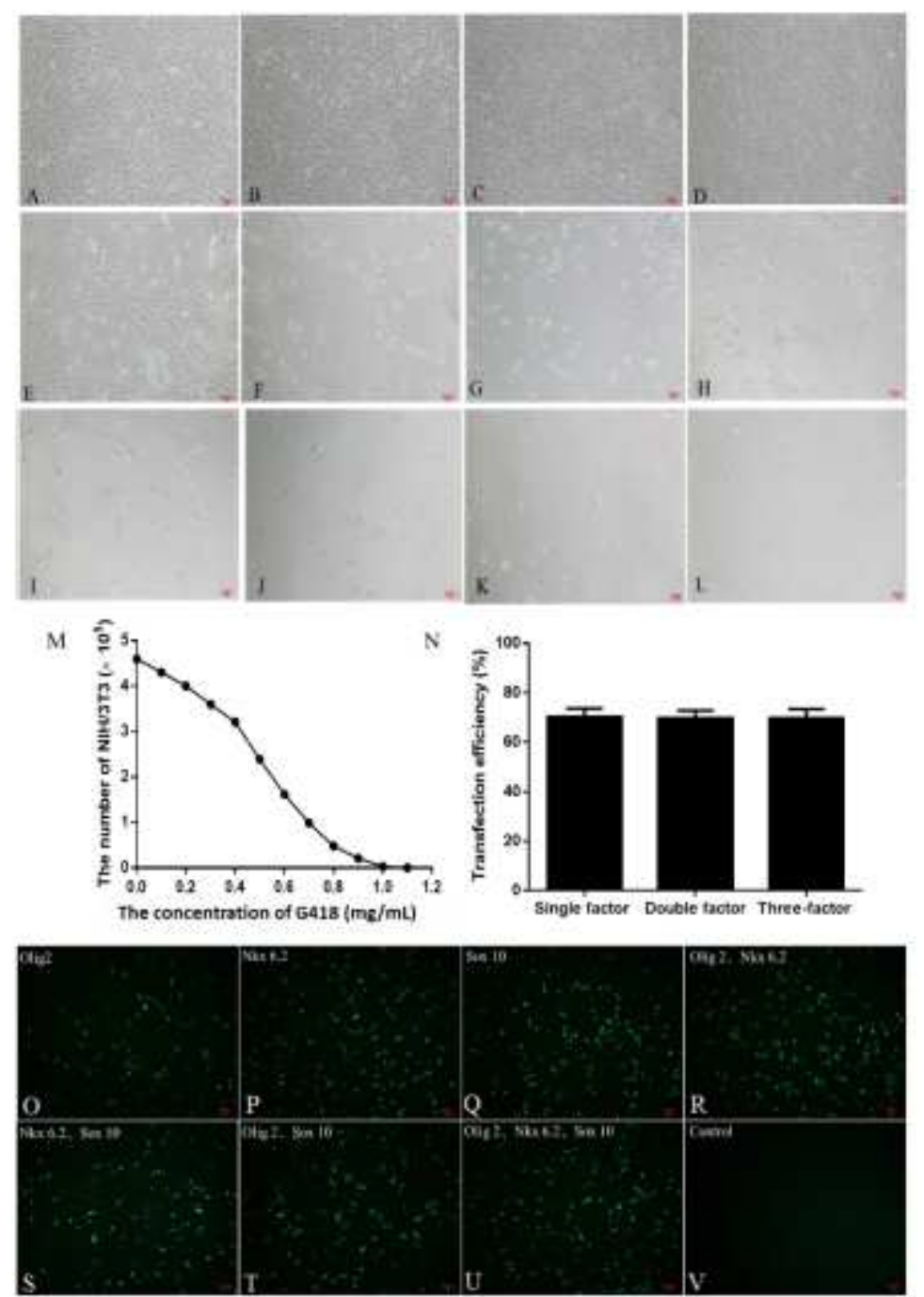

\section{Figure 4}

Transfection of Poly-MAG-delivered pDNA in NIH/3T3 cells a-l. Growth status of NIH/3T3 cells after being treated with G418 at different concentrations for 14 days (a. Control group; b. $0.1 \mathrm{mg} / \mathrm{mL}$ G418; c. 0.2 mg/mL G418; d. 0.3 mg/mL G418; e. 0.4 mg/mL G418; f. 0.5 mg/mL G418; g. 0.6 mg/mL G418; h. 0.7 $\mathrm{mg} / \mathrm{mL}$ G418; i. $0.8 \mathrm{mg} / \mathrm{mL}$ G418; j. 0.9 mg/mL G418; k. $1.0 \mathrm{mg} / \mathrm{mL}$ G418; I. 1.1 mg/mL G418. Bar=25 $\mu \mathrm{m}) ; \mathrm{m}$. The number of $\mathrm{NIH} / 3 \mathrm{~T} 3$ cells after being treated with $\mathrm{G} 418$ at different concentrations for 14 days; n. Poly-MAG-mediated transfection efficiencies of different combinations of transcription factor(s); o-v. EGFP+ NIH/3T3 cells transfected with different kinds of pDNA (o. Olig 2; p. Nkx 6.2; q. Sox 10; r. Olig 2 and Nkx 6.2; s. Sox 10 and Nkx 6.2; t. Olig 2 and Sox 10; u. Olig 2, Nkx 6.2 and Sox 10; v. Control group. Bar=25 $\square \mathrm{m})$. 

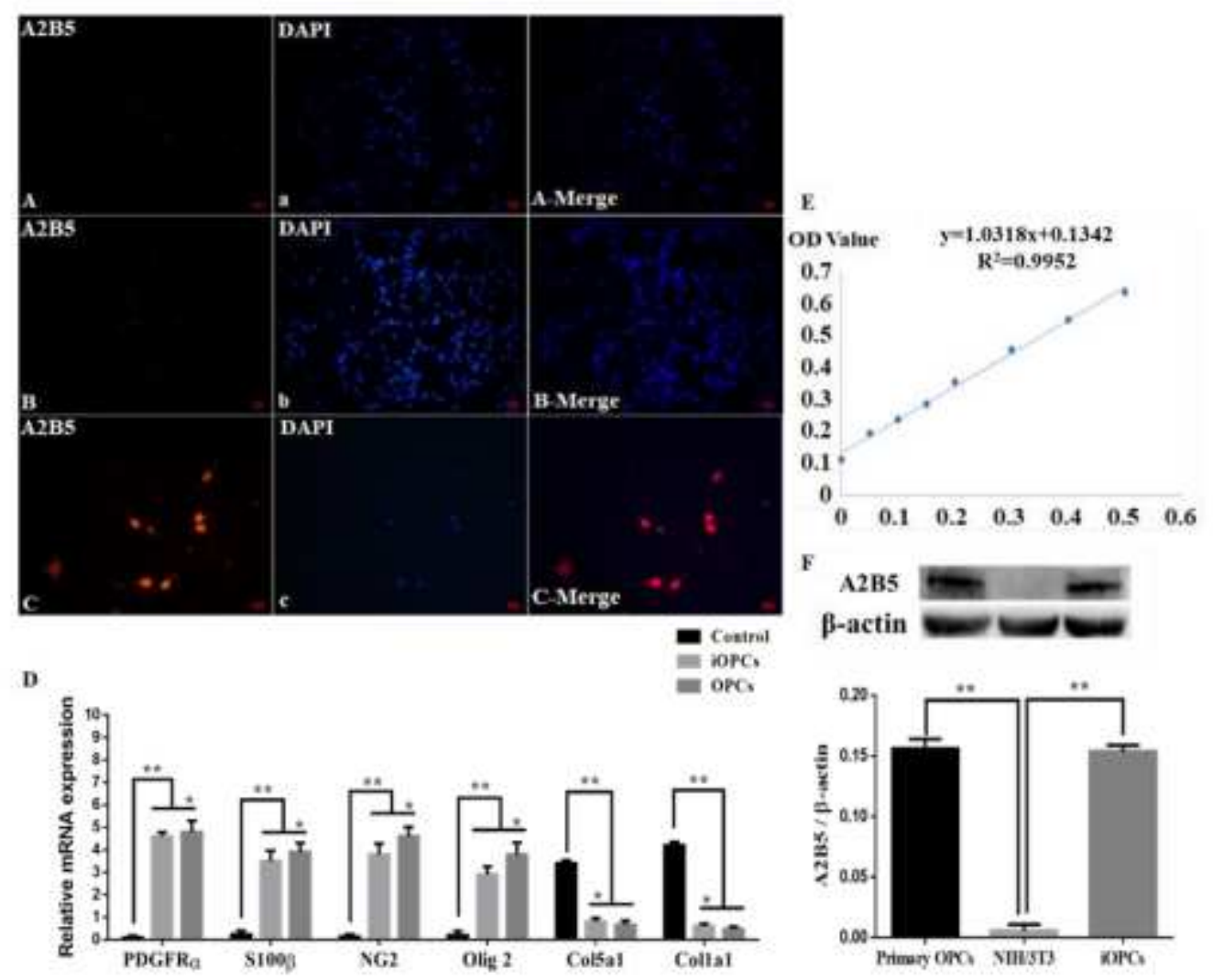

\section{Figure 5}

Generation and identification of iOPCs a-c. Immunocytochemical staining of reprogrammed NIH/3T3 cells which were transfected with different kinds of transcription factors (a. One. b. Two. c. Three. a-b: $B a r=25 \square m$; c: Bar=20 Dm); d. The relative expression quantities of different types of mRNA in NIH/3T3 cells, iOPCs, and mouse primary OPCs; e-f. Expression of A2B5 protein in NIH/3T3 cells, iOPCs, and mouse primary OPCs (e. Standard curve of total protein. f. Expression of A2B5 protein). ${ }^{*} \mathrm{P}<0.05$, ** $\mathrm{P}<0.01$. 

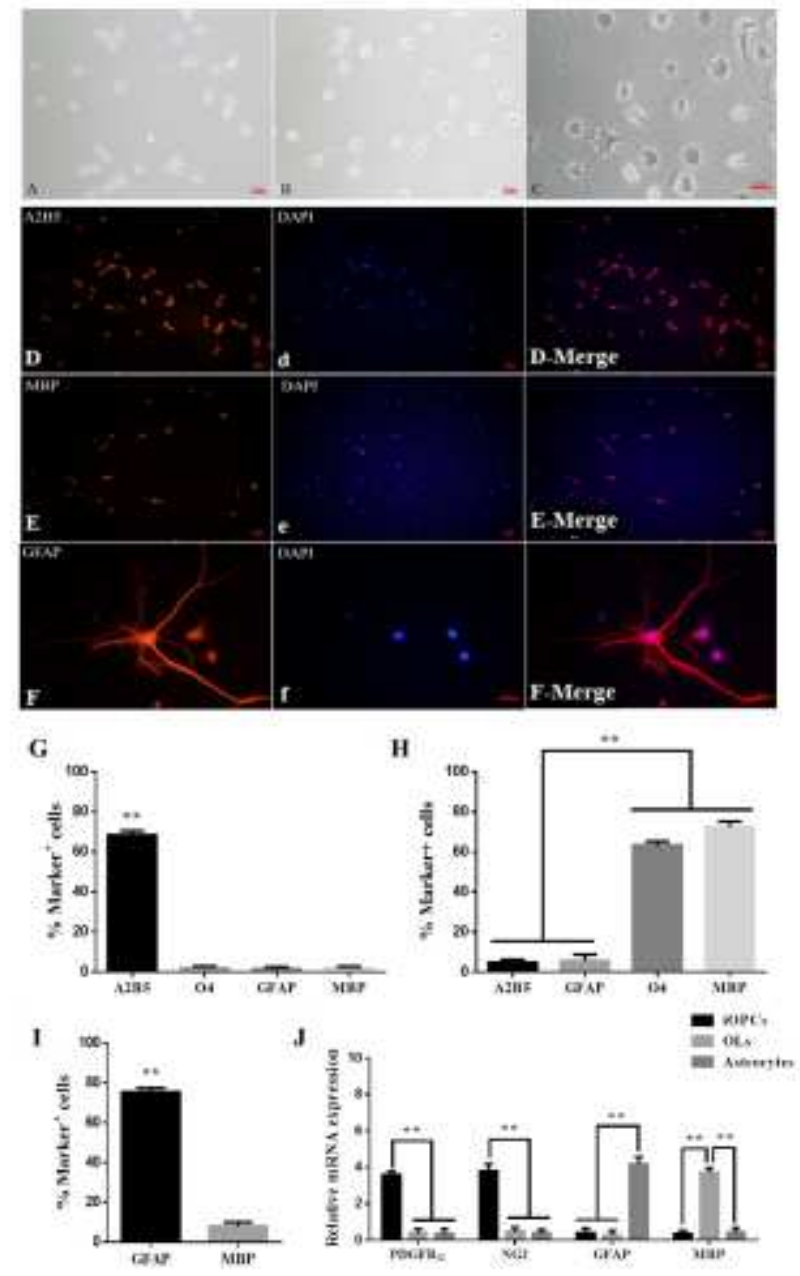

\section{Figure 6}

Induced differentiation of iOPCs in vitro a-c. Morphological observation (a. iOPCs; b. iOPC-derived OLs; c.

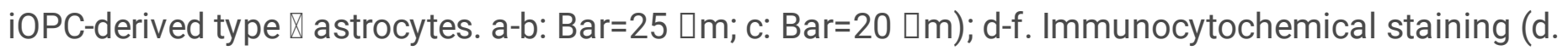
iOPCs; e. iOPC-derived OLs; f. iOPC-derived type $₫$ astrocytes. d-e: Bar=25 पm; f: Bar=20 $\square \mathrm{m}$ ); g-i.

Percentage of special marker+ cells in different kinds of cells (g. iOPCs; h. iOPC-derived OLs; i. iOPCderived type $₫$ astrocytes); j. Relative expression quantities of different mRNA in iOPCs, OLs, and type $₫$ astrocytes. ** $\mathrm{P}<0.01$.

\section{Supplementary Files}

This is a list of supplementary files associated with this preprint. Click to download.

- SupplementaryMaterial.pdf

- SupplementaryMaterial.pdf 